\title{
The desire and capability of Australian general practitioners to change their working hours
}

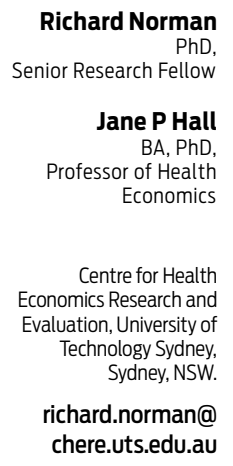

MJA 2014; 200: 399-402 doi: 10.5694/mjal3.10776

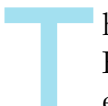

he Australian Institute of Health and Welfare (AIHW) estimated that the number of primary care practitioners in 2009 was 25707, a significant increase from 20616 in $1999 .{ }^{1}$ While general practitioner numbers have risen, the number of hours worked by a typical GP has fallen. The AIHW Medical Labour Force Survey estimated that, over the same period, the mean weekly hours worked fell from 45.6 to 42.2 . In the context of an ageing population, the demand for GPs is likely to continue to rise over time. Recent workforce policy established a number of new medical school places to increase the supply of medical graduates. However, the effects on the availability of GP services will be reduced if working hours continue to decline. Based on existing patterns of demand growth and supply, Health Workforce Australia has predicted a shortfall in doctors in 2025, with an increased reliance on poorly coordinated skilled migration to meet workforce requirements. ${ }^{2}$ The issue of GP labour is particularly acute in rural areas. In 2010, the National Primary Health Care Strategic Framework stated that the number of GPs per 100000 population varies from under 60 in very remote Australia to almost 200 in major cities. $^{3}$

The workload of a GP is likely to be a function of a number of factors. Preferences for reducing the numbers of hours worked, or for changing the type of work undertaken, are likely to depend on a range of characteristics of the doctor, such as age, job satisfaction, and family circumstances. Job satisfaction of Australian doctors is correlated with good support networks, realistic expectations, self-assessed health and income, among other things. ${ }^{4}$ These findings are largely corroborated in the international literature. ${ }^{5}$ In the United States, it has been demonstrated that

\section{Abstract \\ Objective: To explore factors associated with general practitioners' desire to work less and their success in making that change.}

Design, participants and setting: Waves 3 and 4 (conducted in 2010 and 2011) of a national longitudinal survey of Australian doctors in clinical practice (Medicine in Australia: Balancing Employment and Life). Of the broader group of medical practitioners in the survey, there were 3664 and 3436 GP completers in Waves 3 and 4, respectively.

Main outcome measures: The association between the desire to reduce hours and doctor, job and geographic characteristics; the association between predictors of the capability to reduce hours and these same doctor, job and geographic characteristics.

Results: Over $40 \%$ of GPs stated a preference to reduce their working hours. Characteristics that predicted this preference were being middle-aged, being female, working $\geqslant 40$ hours per week (all $P<0.01$ ), and being on call $(P=0.03$ ). Factors associated with not wanting to reduce working hours were being in excellent health, being satisfied or very satisfied with work (both $P<0.01$ ), and not being a partner in a practice $(P<0.01$ for a number of alternative options [ie, associates, contractors and locums]). Of those who wanted to reduce working hours, $26.8 \%$ successfully managed to do so in the subsequent year (where reduction was defined as reducing hours by at least 5 per week). Predictors of successfully reducing hours were being younger, female and working $\geqslant 40$ hours per week (all $P<0.01$ ).

Conclusion: A number of factors appear to determine both the desire of GPs to reduce hours and their subsequent success in doing so. Declining working hours have contributed to the perceived shortage in GPs. Therefore, designing policies that address not just the absolute number of medical graduates but also their subsequent level of work may alleviate some of the pressures on the Australian primary health care system.

dissatisfaction with a medical career was a strong predictor of reducing hours per week below 20, and of retiring altogether. ${ }^{6}$

Thus, a better understanding of doctors' work-participation intentions and how they change their labour supply is a sound basis for developing workforce policy. We aim to investigate two linked issues in the determination of GP working hours. First, by using a 2010 cross-section of an ongoing longitudinal study, we consider the stated preference for changing working hours, to identify the factors influencing GPs' preference for reducing working hours. Second, using the longitudinal nature of the data, we explore whether doctors were able to change their working hours in line with their previously stated preference.
The separation of the issue into two components is valuable, as it helps to identify whether changing working hours is being driven by doctor preferences or by external factors that help or impede doctors to reduce their time commitment to care delivery.

\section{Methods}

The data sources for our analysis were the two most recent waves (Waves 3 and 4, conducted in 2010 and 2011 respectively) of the Medicine in Australia: Balancing Employment and Life (MABEL) survey. ${ }^{7}$ It has been employed to explore, among other things, the determinants of doctors' earnings, work-life balance, and junior doctors' preference for specialty. ${ }^{8-10}$ The Wave 1 (2008) panel of this survey 
consisted of a census of 54750 doctors listed in the Medical Directory of Australia. ${ }^{11}$ Of those invited to participate, 10498 responses were collected. The survey has been administered in three further years, allowing longitudinal exploration of the data. In subsequent waves, those who had responded to previous waves and doctors new to the Directory were invited to participate. The total number of invitations in Waves 3 and 4 were 16327 and 15967, respectively, yielding 9949 and 9773 responses. These consisted of both GPs and hospital-based doctors, of whom $30 \%-40 \%$ were GPs.

Three modifications were made to the dataset before analysis. Annual net personal income was converted into quintiles (defined as $<\$ 60000$, \$60 000-\$84 999, \$85000-\$119999, $\$ 120000-\$ 155999$ and $\geqslant \$ 156000)$. A sixth category for those who did not disclose income was included. Second, family circumstances were considered using a composite variable that included both whether the GP had children and whether they had a partner. The composite variable took on a value representing each of the four possible combinations of these two variables. Third, the number of hours currently worked was grouped into categories of <20, 20-39.5, 40-59.5 and $\geqslant 60$ hours per week.

The determinants of desire to reduce workload used Wave 3 data collected in 2010. The dependent variable was whether or not the doctor stated a desire to reduce hours. As only $3 \%$ of the sample stated a willingness to increase their hours, we combined those responses with those who did not want to change. The second part of the analysis focused on those GPs who stated a desire to reduce their hours in Wave 3, and their subsequent change in hours between Waves 3 and 4 . We selected a criterion of reducing weekly working hours by 5 or more.

The independent variables were age (linear and quadratic); sex; selfassessed health; family circumstance; work satisfaction; weekly working hours; whether the GP was required to do on-call work; the business relationship the GP had with their main practice (principal or partner, associate, salaried, contracted, locum, other); whether the practice was metropolitan, inner regional or other (outer regional, remote, very remote); income quin-

1 Characteristics of doctors who completed Wave 3 of the MABEL survey, and the association between general practitioners stating a desire to reduce working hours and these characteristics* $(n=3377)$

\begin{tabular}{|c|c|c|c|}
\hline Characteristic & Proportion ${ }^{\dagger}$ & Odds ratio $(95 \% \mathrm{Cl})$ & $P$ \\
\hline Mean (SD) age, years & $49.54(11.31)$ & $1.17(1.09-1.25)$ & $<0.01$ \\
\hline Mean age $2 / 100(S D)$ & $25.82(11.52)$ & $0.87(0.81-0.94)^{\ddagger}$ & $<0.01$ \\
\hline Female & $49 \%$ & $1.36(1.11-1.67)$ & $<0.01$ \\
\hline \multicolumn{4}{|l|}{ Self-assessed health } \\
\hline Excellent & $33 \%$ & $0.59(0.45-0.76)$ & $<0.01$ \\
\hline Very good & $36 \%$ & $0.85(0.66-1.10)$ & 0.22 \\
\hline Good $^{\xi}$ & $20 \%$ & 1.00 & \\
\hline Fair & $7 \%$ & $1.25(0.83-1.88)$ & 0.29 \\
\hline Poor & $1 \%$ & $0.42(0.19-0.97)$ & 0.04 \\
\hline Not disclosed & $3 \%$ & $0.66(0.32-1.36)$ & 0.26 \\
\hline \multicolumn{4}{|l|}{ Family circumstance } \\
\hline Single $e^{\varsigma}$ & $11 \%$ & 1.00 & \\
\hline Partner but no children & $27 \%$ & $1.19(0.85-1.66)$ & 0.32 \\
\hline Children but no partner & $5 \%$ & $0.75(0.46-1.22)$ & 0.25 \\
\hline Children and partner & $57 \%$ & $1.02(0.74-1.40)$ & 0.90 \\
\hline \multicolumn{4}{|l|}{ Work satisfaction } \\
\hline Very dissatisfied & $1 \%$ & $1.05(0.37-2.94)$ & 0.93 \\
\hline Dissatisfied & $6 \%$ & $1.29(0.71-2.34)$ & 0.41 \\
\hline Neither satisfied nor dissatisfied ${ }^{\zeta}$ & $5 \%$ & 1.00 & \\
\hline Satisfied & $50 \%$ & $0.50(0.31-0.79)$ & $<0.01$ \\
\hline Very satisfied & $38 \%$ & $0.17(0.11-0.28)$ & $<0.01$ \\
\hline \multicolumn{4}{|l|}{ Weekly working hours } \\
\hline$<20$ & $10 \%$ & $0.21(0.13-0.33)$ & $<0.01$ \\
\hline $20-39.5^{5}$ & $38 \%$ & 1.00 & \\
\hline $40-59.5$ & $41 \%$ & $3.22(2.58-4.03)$ & $<0.01$ \\
\hline$\geqslant 60$ & $8 \%$ & $6.61(4.39-9.96)$ & $<0.01$ \\
\hline Not disclosed & $3 \%$ & $1.69(0.80-3.57)$ & 0.17 \\
\hline On call & $41 \%$ & $1.27(1.02-1.57)$ & 0.03 \\
\hline \multicolumn{4}{|l|}{ Position in practice } \\
\hline Principal or partner & $29 \%$ & 1.00 & \\
\hline Associate & $9 \%$ & $0.61(0.44-0.82)$ & $<0.01$ \\
\hline Salaried & $9 \%$ & $0.72(0.51-1.02)$ & 0.07 \\
\hline Contracted & $47 \%$ & $0.55(0.44-0.68)$ & $<0.01$ \\
\hline Locum & $2 \%$ & $0.27(0.13-0.56)$ & $<0.01$ \\
\hline Other & $4 \%$ & $0.76(0.38-1.53)$ & 0.44 \\
\hline \multicolumn{4}{|l|}{ Region } \\
\hline Metropolitan & $63 \%$ & 1.00 & \\
\hline Inner regional & $22 \%$ & $0.87(0.66-1.14)$ & 0.31 \\
\hline Outer regional, remote or very remote & $15 \%$ & $0.78(0.58-1.04)$ & 0.09 \\
\hline \multicolumn{4}{|l|}{ Personal income } \\
\hline$<\$ 60000$ & $13 \%$ & $0.58(0.41-0.83)$ & $<0.01$ \\
\hline$\$ 60000-\$ 84999$ & $12 \%$ & $0.85(0.61-1.17)$ & 0.31 \\
\hline$\$ 85000-\$ 119999^{\$}$ & $16 \%$ & 1.00 & \\
\hline$\$ 120000-\$ 155999$ & $10 \%$ & $1.27(0.87-1.86)$ & 0.22 \\
\hline$\geqslant \$ 156000$ & $12 \%$ & $0.98(0.70-1.35)$ & 0.88 \\
\hline Not disclosed & $37 \%$ & $0.73(0.56-0.94)$ & 0.01 \\
\hline
\end{tabular}

MABEL = Medicine in Australia: Balancing Employment and Life. ${ }^{7} *$ Geographical characteristics (proportion of patients aged $<5$ or $>65$ years, and number of GPs per 1000 population) not reported as they were statistically non-significant in any model (however, they were controlled for in our results and are available on request). $†$ Unless otherwise specified. $¥$ Negative effect for age squared: mitigates the effect of age at higher levels; turning point (ie, the maximum desire to reduce hours) occurred at 56 years of age. $\$$ Reference characteristic.

tiles; and measures of density of GPs (defined as number of GPs per 1000 population) and composition of patients (the proportion of patients aged $<5$ years or $>65$ years). In addition to running a pooled analysis with both male and female GPs, separate analyses were run for each sex. 
We used ordinary logistic regression using Stata version 12.1 (StataCorp), using weights included in the MABEL survey to ensure representativeness of the sample to the Australian GP population. Sensitivity analyses to test the robustness of the findings to the decision to limit to the most recent waves of data (ie, Waves 3 and 4) and to the use of a 5-hour cut-off to denote a reduction in hours resulted in similar results (available on request).

\section{Results}

Of the 3377 GPs from Wave 3 included in the analysis, $43 \%$ stated a desire to reduce hours. The regression results are presented in Box 1. Age was a strong positive predictor of desire to reduce hours $(P<0.01)$, although the negative effect for age squared suggests that the increase slows and even reverses in higher age groups. Female doctors were more likely to want to reduce hours (odds ratio [OR], 1.36; 95\% CI, 1.11-1.67; $P<0.01)$. Those who reported excellent health were less likely to want to reduce hours than those reporting good health (OR, 0.59; 95\% CI, $0.45-0.76 ; P<0.01)$. Those who were satisfied (OR, 0.50; 95\% CI, $0.31-0.79 ; P<0.01)$ or very satisfied (OR, 0.17; 95\% CI, 0.11-0.28; P<0.01) with their work were less likely to want to reduce hours relative to those who were neither satisfied nor dissatisfied. Working hours strongly predicted the desire to reduce hours; relative to a GP working 20-39.5 hours per week, a GP working $\geqslant 60$ hours per week was over six times more likely to want to reduce hours. Partners were most likely to want to reduce their working hours. Associates, contracted GPs and locums were all less likely to want to reduce their hours (all $P<0.01$ ) compared with partners. There was a weak income effect - doctors in the higher quintiles were more likely to state a desire to reduce their hours, although statistical significance was only achieved for the difference between those in the first and third quintiles (ie, doctors earning $<\$ 60000$ per year compared with those earning \$85000\$119999 per year).

When the analysis was run for each sex separately (results available on request), the notable age effect was driven by male GPs. That is, the associ-

2 Characteristics of doctors who completed Waves 3 and 4 of the MABEL survey, and the association between general practitioners reducing weekly hours by 5 or more and these characteristics* $(n=1143)$

\begin{tabular}{|c|c|c|c|}
\hline Characteristic & Proportion $^{\dagger}$ & Odds ratio $(95 \% \mathrm{Cl})$ & $P$ \\
\hline Mean (SD) age, years & $50.73(10.02)$ & $0.75(0.66-0.85)$ & $<0.01$ \\
\hline Mean age $2 / 100$ (SD) & $26.74(10.00)$ & $1.35(1.18-1.54)^{\ddagger}$ & $<0.01$ \\
\hline Female & $42 \%$ & $1.91(1.32-2.75)$ & $<0.01$ \\
\hline \multicolumn{4}{|l|}{ Self-assessed health } \\
\hline Excellent & $26 \%$ & $0.87(0.55-1.38)$ & 0.56 \\
\hline Very good & $38 \%$ & $0.93(0.61-1.41)$ & 0.72 \\
\hline Good $^{\xi}$ & $26 \%$ & 1.00 & \\
\hline Fair & $9 \%$ & $0.83(0.45-1.53)$ & 0.54 \\
\hline Poor & $1 \%$ & $0.52(0.13-2.07)$ & 0.36 \\
\hline \multicolumn{4}{|l|}{ Family circumstance } \\
\hline Single $e^{\S}$ & $10 \%$ & 1.00 & \\
\hline Partner but no children & $29 \%$ & $0.95(0.52-1.75)$ & 0.88 \\
\hline Children but no partner & $5 \%$ & $1.49(0.65-3.43)$ & 0.35 \\
\hline Children and partner & $56 \%$ & $0.99(0.56-1.74)$ & 0.96 \\
\hline \multicolumn{4}{|l|}{ Work satisfaction } \\
\hline Very dissatisfied & $1 \%$ & $0.44(0.08-2.46)$ & 0.35 \\
\hline Dissatisfied & $11 \%$ & $1.04(0.43-2.55)$ & 0.93 \\
\hline Neither satisfied nor dissatisfied ${ }^{\delta}$ & $5 \%$ & 1.00 & \\
\hline Satisfied & $59 \%$ & $0.86(0.40-1.88)$ & 0.71 \\
\hline Very satisfied & $24 \%$ & $0.57(0.25-1.33)$ & 0.20 \\
\hline \multicolumn{4}{|l|}{ Weekly working hours } \\
\hline$<20$ & $2 \%$ & $1.17(0.31-4.44)$ & 0.82 \\
\hline $20-39.5^{\S}$ & $28 \%$ & 1.00 & \\
\hline $40-59.5$ & $54 \%$ & $1.97(1.30-3.00)$ & $<0.01$ \\
\hline$\geqslant 60$ & $16 \%$ & $7.71(4.47-13.31)$ & $<0.01$ \\
\hline On call & $51 \%$ & $0.85(0.59-1.23)$ & 0.40 \\
\hline \multicolumn{4}{|l|}{ Position in practice } \\
\hline Principal or partner ${ }^{\delta}$ & $41 \%$ & 1.00 & \\
\hline Associate & $11 \%$ & $1.26(0.77-2.08)$ & 0.36 \\
\hline Salaried & $9 \%$ & $0.97(0.49-1.92)$ & 0.94 \\
\hline Contracted & $37 \%$ & $0.79(0.53-1.18)$ & 0.25 \\
\hline Locum & $1 \%$ & $1.90(0.55-6.50)$ & 0.31 \\
\hline Other & $1 \%$ & $0.87(0.26-2.91)$ & 0.82 \\
\hline \multicolumn{4}{|l|}{ Region } \\
\hline Metropolitan & $61 \%$ & 1.00 & \\
\hline Inner regional & $23 \%$ & $1.28(0.84-1.96)$ & 0.25 \\
\hline Outer regional, remote or very remote & $16 \%$ & $1.49(0.92-2.42)$ & 0.11 \\
\hline \multicolumn{4}{|l|}{ Personal income } \\
\hline$<\$ 60000$ & $8 \%$ & $1.14(0.56-2.33)$ & 0.71 \\
\hline$\$ 60000-\$ 84999$ & $12 \%$ & $0.79(0.41-1.51)$ & 0.47 \\
\hline$\$ 85000-\$ 119999^{\$}$ & $16 \%$ & 1.00 & \\
\hline$\$ 120000-\$ 155999$ & $12 \%$ & $0.65(0.35-1.21)$ & 0.17 \\
\hline$\geqslant \$ 156000$ & $18 \%$ & $0.85(0.48-1.51)$ & 0.58 \\
\hline Not disclosed & $34 \%$ & $1.24(0.77-1.99)$ & 0.38 \\
\hline
\end{tabular}

MABEL = Medicine in Australia: Balancing Employment and Life. ${ }^{7} *$ Geographical characteristics (proportion of patients aged < 5 or $>65$ years, and number of GPs per 1000 population) not reported as they were statistically non-significant in any model (however, they were controlled for in our results and are available on request). $\dagger$ Unless otherwise specified. $¥$ Positive effect for age squared: mitigates the effect of age at higher levels; turning point (ie, the minimum capacity to reduce hours) occurred at 50 years of age. $\$$ Reference characteristic.

ation between age and stating a preference to reduce working hours was very strong in males $(P<0.01$ for both the linear and quadratic terms), but not in female GPs. Middle-aged men were most likely to state a desire to reduce working hours, with a maximum desire occurring at 56 years of age.

Two thousand seven hundred and twenty GPs had complete workinghours data for both Waves 3 and 4, 1177 of whom had stated a desire to 
reduce their hours in Wave 3. Of these, $316(26.8 \%)$ successfully reduced their weekly hours by more than 5 . Of the 861 doctors who were unable to reduce their hours despite stating that preference, $647(75.1 \%)$ continued to state a desire to reduce working hours in Wave 4 , suggesting that their failure to reduce hours was not due to changing preferences, but to external factors preventing a reduction in working hours. The regression results are reported in Box 2 . The ability to reduce hours was predicted by three factors: age, sex and the number of hours currently worked. Regarding age, there was a U-shaped relationship suggesting that middleaged doctors (around 50 years of age) are the least likely to achieve desired reduction in hours. Female doctors were more likely to successfully reduce hours (OR, 1.91; 95\% CI, 1.32-2.75; $P<0.01)$. Doctors working longer hours were more likely to successfully reduce hours. For doctors working 40 59.5 hours per week, the OR was 1.97 (95\% CI, 1.30-3.00; $P<0.01$ ) and for those working $\geqslant 60$ hours per week, the OR rose to $7.71(95 \% \mathrm{CI}, 4.47$ 13.31; $P<0.01)$.

\section{Discussion}

This study explored two linked issues affecting GPs' ability to reduce their working hours: the factors associated with GPs wanting to work less, and the factors that appear to allow them to reduce their hours. The advantage of separating the two issues is that it allows exploration of how policy responses might impact on working hours.

Our results show that GPs stating a desire to reduce hours are generally middle-aged, women, working longer hours or required to work on call. If the GP is a partner or principal in the practice, he or she is more likely to state the preference to reduce hours in future. This may reflect the higher pressure on partners and principals, both financially and in terms of workload. Regarding on-call work, it is important to note that the result remained even when we controlled for working hours. Therefore, the provision of these services, which may be extended under the rollout of Medicare Locals, makes it likely that the propor- tion of GPs looking to reduce their workload will increase.

High levels of job satisfaction are also less likely to be associated with the desire to reduce working hours. It is difficult to determine whether satisfaction with working hours is a major determinant of overall job satisfaction, or whether the causality runs in the reverse direction. Nonetheless, we believe that enhancing attractive job features may well be a viable policy option for increasing doctor availability.

One potential issue with this type of analysis is the generalisability of the result to the Australian GP population. The population weights supplied in the MABEL survey ensure generalisability in terms of age, sex and location only. However, the MABEL survey represents a relatively large proportion of the Australian GP population, reducing the risk of volunteer bias. Additionally, the GP characteristics over which the MABEL survey is population-weighted represent those for which we are likely to have wholepopulation data. Our results also show that most of the GPs who wish to reduce their working hours fail (or are unable) to do so within the next year. The key predictors of reducing hours are age, sex and current working hours. Middle-aged doctors are least likely to reduce their hours. Female GPs are more likely to reduce hours if they want to do so. These results are robust to other factors that might explain these relationships (eg, practice ownership, family circumstance and income). This may be due to different motivations. Family constraints are more pressing for younger GPs and female GPs, while older male GPs are contemplating moving to retirement gradually. The variables that matter in predicting GPs' success in reducing hours are either working hours themselves or demographic characteristics that cannot be changed through policy levers. The implication of this is that policy designed to retain labour supply in the health workforce should focus on the predictors of the desire to reduce hours (Box 1 ).

There is an increasing emphasis on the development of policy based on research evidence, but to date there has been little insight into doctors' changing work patterns. Our results show that improved GP job satisfaction is associated with less desire to reduce working hours. This implies that further investigation of policies that can improve GP job satisfaction may well ensure improvements in the doctor supply, which are needed to meet the increasing demand for primary care into the future. Meeting the needs of the population for primary health care and supporting those providing this care represents an important balance that must be made, and an area of ongoing challenge and opportunity.

Acknowledgements: This research is a project of the Australian Primary Health Care Research Institute, supported by a grant from the Australian Government Department of Health. The information and opinions contained in it do not necessarily reflect the views or policies of these organisations. This publication used data from the MABEL longitudinal survey of doctors conducted by the University of Melbourne and Monash University. The MABEL survey is funded by the National Health and Medical Research Council and the Department of Health. The MABEL research team bears no responsibility for how the data have been analysed, used or summarised in this article Competing interests: No relevant disclosures.

Received 12 Jun 2013, accepted 26 Nov 2013

1 Australian Institute of Health and Welfare. Medical labour force 2009. Canberra: AlHW, 2011. (AlHW Bulletin No. 89; AlHW Cat. No. AUS 138.) http:// www.aihw. gov.au/publication-detail/?id= 10737419680 (accessed Nov 2013).

2 Health Workforce Australia. Health Workforce 2025: doctors, nurses and midwives. Vol. 1. Canberra: HWA, 2012. http://www.hwa.gov.au/sites/uploads/ FinalReport_Volumel_FINAL-20120424.pdf (accessed Nov 2013).

3 Department of Health and Ageing. Building a 21st century primary health care system: Australia's first national primary health care strategy. Canberra: Commonwealth of Australia, 2010. http://www. yourhealth.gov.au/internet/your health/publishing. nsf/Content/3EDF5889BEC 00D98CA257954 0005F0A4/\$File/6552\%20 NPHC\%201205.pdf (accessed May 2013).

4 Joyce CM, Schurer S, Scott A, et al. Australian doctors' satisfaction with their work: results from the MABEL longitudinal survey of doctors. Med J Aust 2011; 194: 30-33.

5 Van Ham I, Verhoeven AA, Groenier KH, et al. Job satisfaction among general practitioners: a systematic literature review. Eur J Gen Pract 2006; 12:174-180.

6 Landon BE, Reschovsky JD, Pham HH, BlumenthalD. Leaving medicine: the consequences of physician dissatisfaction. Med Care 2006; 44: 234-242.

7 Yan W, Li J, Scott A, et al. MABEL user manual: wave 4 release. Melbourne: Melbourne Institute of Applied Economic and Social Research, University of Melbourne, 2013. https://mabel.org. au/ dataMABEL\%20User\%20Manual\%20 Wave $\% 204 \% 20$ Release_v4.0.pdf (accessed Nov 2013).

8 Sivey P, Scott A, Witt J, et al. Junior doctors' preferences for specialty choice. J Health Econ 2012; 31: 813-823.

9 Cheng TC, Scott A, Jeon SH, et al. What factors influence the earnings of general practitioners and medical specialists? Evidence from the medicine in Australia: balancing employment and life survey. Health Econ 2012; 21: 1300-1317.

10 Shrestha D, Joyce CM. Aspects of work-life balance of Australian general practitioners: determinants and possible consequences. Aust J Prim Health 2011; 17: 40-47.

11 Yan W, Cheng TC, Scott A, et al. Medicine in Australia: Balancing Employment and Life (MABEL). Aust Econ Rev 2011; 44: 102-112. doi: 10.111//.14678462.2010.00627.x 